\title{
sciendo
}

\section{DEVELOPING URBAN GREEN SPACE CLASSIFICATION SYSTEM USING MULTI-CRITERIA: THE CASE OF KUALA LUMPUR CITY, MALAYSIA}

\author{
AMAL NAJIHAH MUHAMAD NOR ${ }^{1,2}$ AND SAIFUL ARIF ABDULLAH ${ }^{1} *$ \\ ${ }^{I}$ Institute for Environment and Development (LESTARI), Universiti Kebangsaan Malaysia, \\ 43600 UKM Bangi, Selangor, Malaysia. \\ ${ }^{2}$ Faculty of Earth Science, Universiti Malaysia Kelantan, Jeli Campus, 17600 Jeli, \\ Kelantan, Malaysia. \\ *Corresponding authore-mail: saiful@ukm.edu.my
}

Received: $25^{\text {th }}$ October 2018, Accepted: $21^{\text {th }}$ December 2018

\begin{abstract}
In many countries urban green spaces are stated in a set of different administrative regulatory framework. However, their definition and characteristics are inconsistent and developing a systematic classification has been recognized to avoid the inconsistency. Several efforts have been made but the approach mainly based on a few criteria and classified manually according to the types that stated in the regulatory framework. Therefore, this study developed a classification system based on multi-criteria that represents the structure and function of urban green spaces using Kuala Lumpur City, Malaysia as a model. The useful of the systematic classification for urban green spaces planning and management was interpreted through landscape pattern analysis. In this study, land use map of Kuala Lumpur City was used as a based. Through field observation, information from Kuala Lumpur City Hall and satellite image interpretation, seven criteria were identified to develop the classification system. Landscape pattern was based on landscape metrics analyzed using FRAGSTAT 3.3. The analysis defined five categories of urban green spaces: conservation green space, greenway, community green space, residential green space and amenity green space. Landscape pattern analysis has allowed to interpret what category needs attention to improve their quality and quantity as well as to protect them from any land use development. It can be assumed that the multi-criteria approach can be considered as a first step to introduce a more systematic way to categorize urban green spaces and addressing the inconsistency issue which is important for the city to develop sustainably.
\end{abstract}

Keywords: City, Green space, Landscape planning, Sustainable development, Urban landscape

\section{INTRODUCTION}

Urban green space is one of the important elements in cities for environmental conservation. Generally, it refers to any green patches including the hard-surface areas that permeable, predominantly consists of 'soft surfaces' such as soil, grass, shrubs and trees (Dunnett et al., 2002; Lee et al., 2015). Thus, urban green spaces are variety such as parks and garden, housing green spaces, city farm, grassland, private green areas, sport field, and 
agricultural areas (e.g Dunnett et al, 2002; Kong \& Nakagoshi, 2006; Panduro \& Veie, 2013; Pena-Salmon et al., 2014). Different countries may have similar or different type of urban green spaces which depends on location, geography, socio-economic, environment and culture of a particular country (e.g Dunnett et al., 2002; Senanayake et al., 2013; Vatseva et al., 2016; Zhang et al., 2007a). The type of urban green spaces are commonly stated in the set of federal, state and, district or municipal regulatory framework (i.e law and regulation) related to urban planning (Dunnet et al., 2002; Peña-Salmón et al., 2014). However, their definition and characteristic are inconsistent or not standardize between states, districts or even in different administrative or management zones of a city (e.g Badiru et al., 2005; Peña-Salmón et al., 2014). In the context of sustainable urban planning the inconsistency may cause urban green spaces planning and management not efficient and possibly fail to achieve sustainable urban development.

Developing a classification system of urban green space categories (hereafter refers as classification system) is one of the approaches to avoid the inconsistency (Gaffin et al., 2009; Owen et al., 2006). The systematic classification can be used by urban planners for urban land use change, urban ecology and urban sprawl studies which are useful to plan and to manage urban land use sustainably (Owen et al., 2006; Wang, 2009). Although several efforts have been made to develop urban green space classification system, the approaches used to develop them mainly based on size and vegetation greenness or green area identified through remote sensing and GIS techniques which then classified manually according to the types that stated in the regulatory framework (e.g Kong \& Nakagoshi, 2007; Peña-Salmón et al., 2014; Ummeh \& Toshio, 2017; Zhang et al., 2007). Nonetheless, urban green spaces may have similar or different structures (e.g size, shape, location) and functions (e.g. recreation, sports facilities, children playground) among them. This reflects that a multi-criteria approach must be considered to develop the classification system.

The requirement to use multi-criteria approach is acknowledged by Bryne \& Sipe (2010) by stating that urban green spaces can be categorized according to several criteria such as size, location and how people use it. This thought was applied by Bilgali \& Gökyer (2012) in categorizing urban green spaces in Turkey by using the three criteria. Based on this, two aspects of criteria for the classification system are identified. They are structure (i.e composition and configuration) and function which both have direct and indirect effects to urban socio-ecological systems. Therefore, among the important criteria that represent the structure aspects include type of vegetation (e.g natural forest, avenue tree and ornamental tree), percentage perimeter of urban green spaces bordering built-up areas, locality of urban green spaces (e.g near residential areas and office buildings) while function includes recreational, education and aesthetic. Generally, the method to develop the classification system based on multi-criteria is still lacking. If any, the classification system was made manually such as by Bilgali \& Gökyer (2012) while Panduro \& Veie (2013) used several sub-criteria of accessibility to categorize urban green spaces by quantifying their impact on house price using hedonic model.

To address the deficit we put our research question as follows: i.) how urban green space classification system can be developed using a multi-criteria approach? and ii.) why the systematic classification is useful for planning and management of urban green spaces? This study used Kuala Lumpur City, Malaysia as a model. The objectives are to develop the classification system based on multi-criteria that represents the structure and function of urban green spaces and to interpret the useful of the systematic classification for urban green spaces planning and management. 


\section{MATERIAL AND METHODS}

\section{Study area}

The capital of Malaysia, Kuala Lumpur City is located at the latitude between $3^{\circ} 2^{\prime} \mathrm{N}$ and $3^{\circ} 15^{\prime} \mathrm{N}$, and longitude between $101^{\circ} 37^{\prime} \mathrm{E}$ and $101^{\circ} 46^{\prime} \mathrm{E}$ (Fig. 1). The total area of the city is about 243,000 ha and situated within Klang Valley which is the fastest growing economic region in the country. The city is divided into six strategic zones namely Sentul-Manjalara, Wangsa Maju-Maluri, Damansara-Penchala, Pusat Bandar, Bukit Jalil-Seputeh and Bandar Tun Razak-Sungai Besi (Fig. 1).

\section{Fig. 1: Location of Kuala Lumpur in peninsular Malaysia}

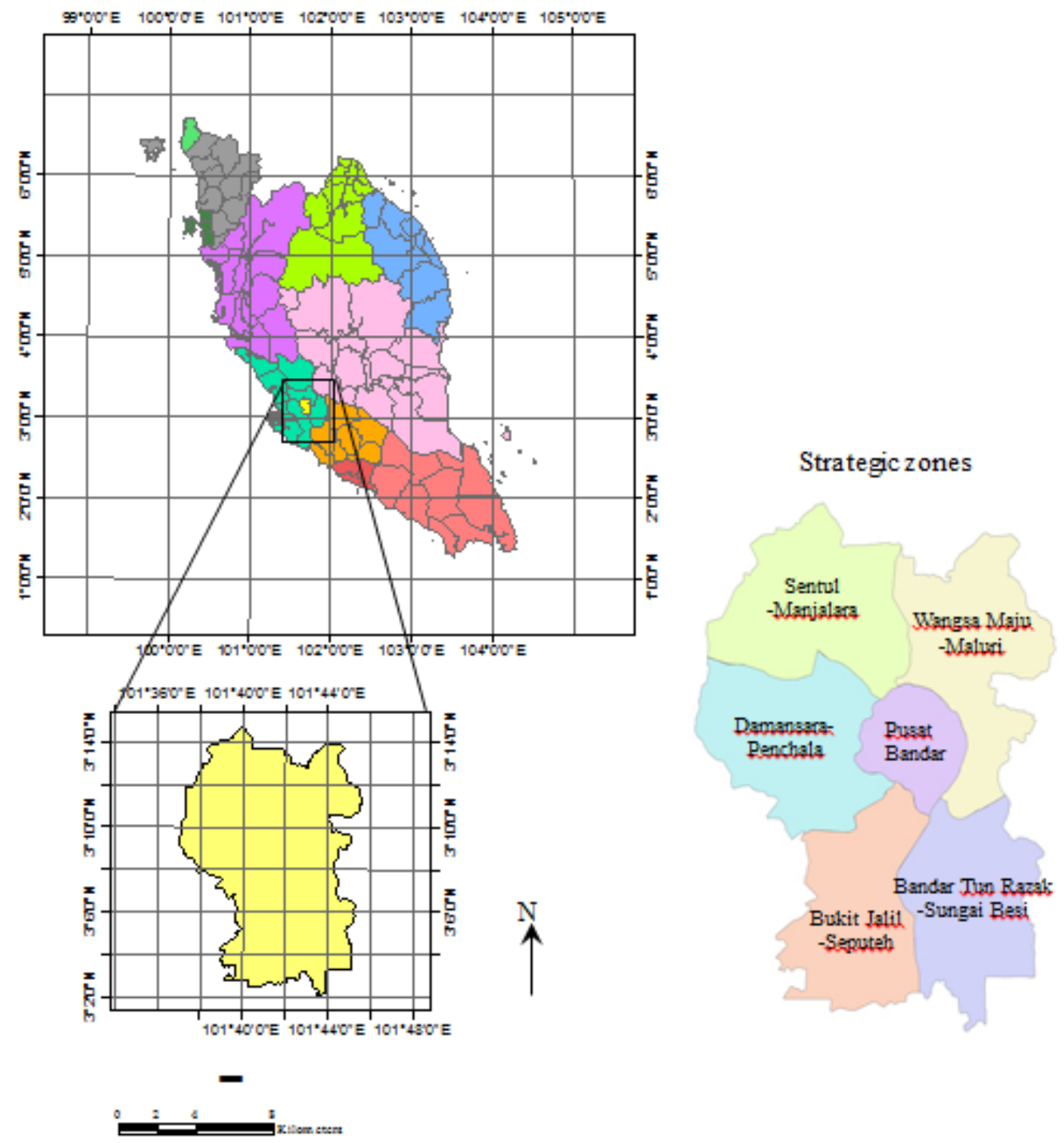


All the strategic zones are administered by Kuala Lumpur City Hall (Kuala Lumpur City Hall, 2004). The altitude of Kuala Lumpur City is 22 meter a.s.l with undulating terrain and small hills scattered throughout the city. Owing located at the equatorial belt the mean annual temperature is ranged between $27^{\circ} \mathrm{C}$ and $33^{\circ} \mathrm{C}$, and the mean annual rainfall is about 2,540 $\mathrm{mm}$ with the highest occurred during October and November (Bunnell et al., 2002).

The socio-economic of Kuala Lumpur is progressing rapidly. For example, the gross domestic product in 2016 (RM190 million) increased by about $68 \%$ from 2010 (RM113 million) (Department of Statistic Malaysia, 2017). The increase came from industrial, banking, transportation, commerce, product and service sectors. In 2020, the service sector is expected to increase by $87 \%$ and become the major contributor to the gross domestic product (Malaysia, 2001). The total population also increases rapidly, for example, in 2017 it was about 1.79 million people which increased about $27 \%$ from 1990. In 2020, the total population is expected to reach about 2.2 million people (Kuala Lumpur City Hall, 2004).

\section{Data acquisition and satellite image processing}

A SPOT satellite image with spatial resolution 2.5 and path/row $127 / 58$ covering the study area was used to develop the land use map of Kuala Lumpur City. Prior to the process, the border of Kuala Lumpur City was overlaid on the image and clipped to produce a single image of the city. The border of the city was geocoded and digitized using ArcGIS 9.2. In the following process, band combination was created by combining bands of spectral data to enhance the particular land use of interest (ERDAS, 1999). In this study, a false colour composite (FCC) of band 5-4-3 was applied because it provides clear image which is suitable to distinguish each land use type compared to the other tested FCC i.e 5-2-1 and 5-3-2. Land use types were identified using supervised classification which performed using the maximum likelihood method (Apan et al., 2000; Jensen, 1996). Through the classification process, the image was classified into four types of land use; water body, vegetation, built-up area and bare land. To improve the quality and reliability of the image, masking is performed to remove pixels that are not needed in this study. This is to reduce the interference in identification of required land use (Sreenivasulu \& Bhaskar, 2010; Xie et al., 2007). In this process, recode function in ERDAS Imagine version 9.1 was used to combine the types of land use in which all the land use needed were represented as a value of 1 while the value 0 for pixels that can not be classified. Then the filtering process was carried out to remove all pixels that are not needed. Through this process, small or isolated pixels can be grouped into large pixels (Akay et al., 2007; Liu, 2000). Then, in the neighborhood function of ERDAS Imagine 9.1, the low-pass filtering 7X7 was selected because it can maximize the results of filtering and removing various unnecessary data to improve image quality and facilitate the assessment of landscape pattern (Yuksel et al., 2008).

The accuracy of the supervised classification was assessed using stratified random sampling scheme. In this assessment a total of 256 points were selected. A contingency table was created by comparing on a class-by-class basis of the land use types with an independent data source such as topographic maps (scale 1:50 000) and field observation. The accuracy information was generated which contained a summary statistic of overall agreement percentage of producer's and user's accuracy (Turner et al., 2001). Based on this assessment, the overall accuracy is 90.6 while Kappa value is 0.87 which means that the land use map is acceptable for further analysis (Table 1). 
Muhammad Nor A. N., Abdullah S. A.: Developing urban green space classification system using multi-criteria: The case of Kuala Lumpur City, Malaysia

Table 1: Overall accuracy assessment and Kappa statistic of the land use image

\begin{tabular}{lccccc}
\hline Land use type & $\begin{array}{c}\text { Reference } \\
\text { totals }\end{array}$ & $\begin{array}{c}\text { Classified } \\
\text { total }\end{array}$ & $\begin{array}{c}\text { Number } \\
\text { correct }\end{array}$ & $\begin{array}{c}\text { Producers } \\
\text { accuracy } \\
(\%)\end{array}$ & $\begin{array}{c}\text { User } \\
\text { accuracy } \\
(\%)\end{array}$ \\
\hline Urban land use & 140 & 140 & 49 & 81.88 & 81.88 \\
Built-up area & 84 & 88 & 80 & 95.24 & 89.89 \\
Cleared-land & 29 & 25 & 20 & 68.97 & 80 \\
Water body & 3 & 3 & 3 & 100 & 100 \\
\hline Overall accuracy $(\%)=90.63$ & & & & \\
Kappa statistic $=0.87$ & & & & & \\
\hline
\end{tabular}

The raster map then was converted to vector format using ArcMap (ver. 9.2). This study focused on urban green spaces managed by Kuala Lumpur City Hall (hereafter referred as urban green space). Therefore, border of urban green spaces derived from the Kuala Lumpur City Hall was geocoded and digitized using ArcGIS 9.2, which then overlaid on the vector land use map. This to produces a new map that indicates the location, distribution and other land use within and surrounding urban green spaces. The total number of urban green spaces is 104 and assigned as S1, S2 till S104. 


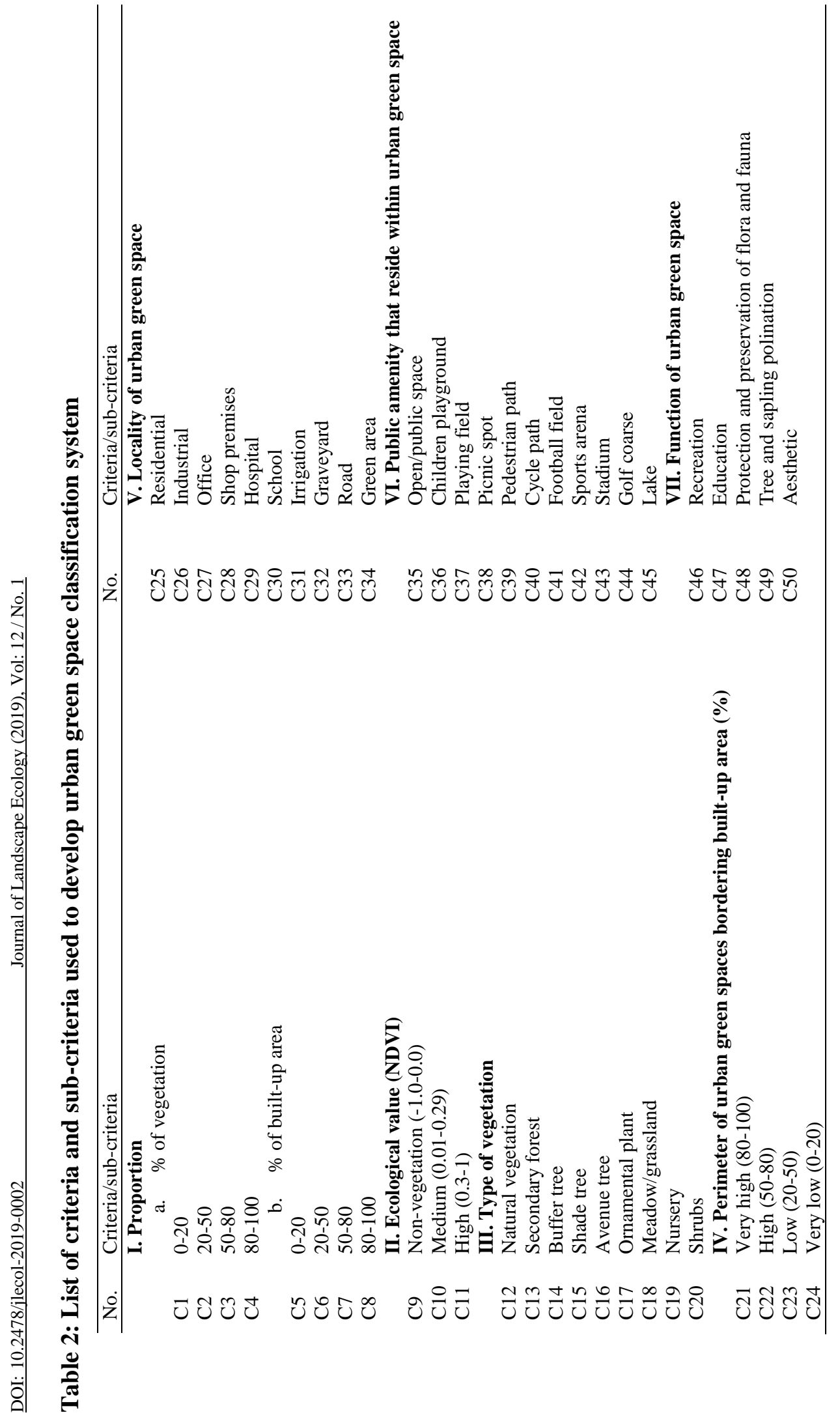




\section{Criteria and sub-criteria}

Selection of criteria (including sub-criteria) for developing urban green space classification system was based on field observation at each urban green space other than the information gathered from Kuala Lumpur City Hall and the vector land use map. Based on the gathered information, seven criteria were identified, i.e i.) Proportion (\%) of vegetation and built up areas that reside within urban green space, ii.) ecological value, iii.) vegetation types, iv.) percentage perimeter of urban green space bordering built-up areas, v.) locality of urban green space, vi.) public amenities that reside within urban green space and vii.) function of urban green space. Each criterion has its own unit or scale. The detail of each criterion and their sub-criteria/scale which represent the structure and function of urban green spaces are presented in Table 2. Field survey was conducted at each urban green space. During the field survey, criteria (including the sub-criteria) such as types of vegetation and public amenities were recorded. The locations of urban green spaces were recorded using global positioning system.

\section{Cluster analysis}

Cluster analysis was conducted to classify urban green spaces based on the criteria/sub-criteria. In the analysis, the Minimum Variant Method (the Ward's Method) was applied which uses the binary and Squared Euclidean Distance measurement using SPSS 15.1 software. The binary measurement was applied to marked all sub-criteria of each criterion of the 104 urban green space as 1 (presence) and 0 (absence). The analysis was conducted, first, without fixing the optimum number of categories of urban green spaces. This process produced an agglomeration schedule which has a possible number of categories of urban green space (Table 3). The schedule also contained the agglomeration (a) and the co-efficient (c) values, and their differences $(a-c=d)$ for each possible class (Table 3). Based on the schedule, the highest differences of $d$ is between 248.67 (five possible class) and 90.43 (six possible class) which mean that the optimum five categories of urban green space was considered (Table 3). Then the same analysis was conducted with categories of urban green spaces was fixed to five. This process produced members for each category (Fig. 2) which finally named and defined.

Table 3: Agglomeration schedule

\begin{tabular}{cccc}
\hline Total type & Agglomeration & Co-efficients & Differences \\
\hline 2 & 2080.74 & 1697.22 & 383.52 \\
3 & 1697.22 & 1361.65 & 335.57 \\
4 & 1361.65 & 1055.07 & 306.58 \\
5 & 1055.07 & 806.41 & 248.67 \\
6 & 806.41 & 715.97 & 90.43 \\
7 & 715.97 & 656.65 & 59.33 \\
8 & 656.65 & 611.2 & 45.44 \\
9 & 611.2 & 573.75 & 37.45 \\
10 & 573.75 & 547.24 & 26.51 \\
\hline
\end{tabular}


Fig. 2: Dendogram of cluster analysis to categorize urban green space.

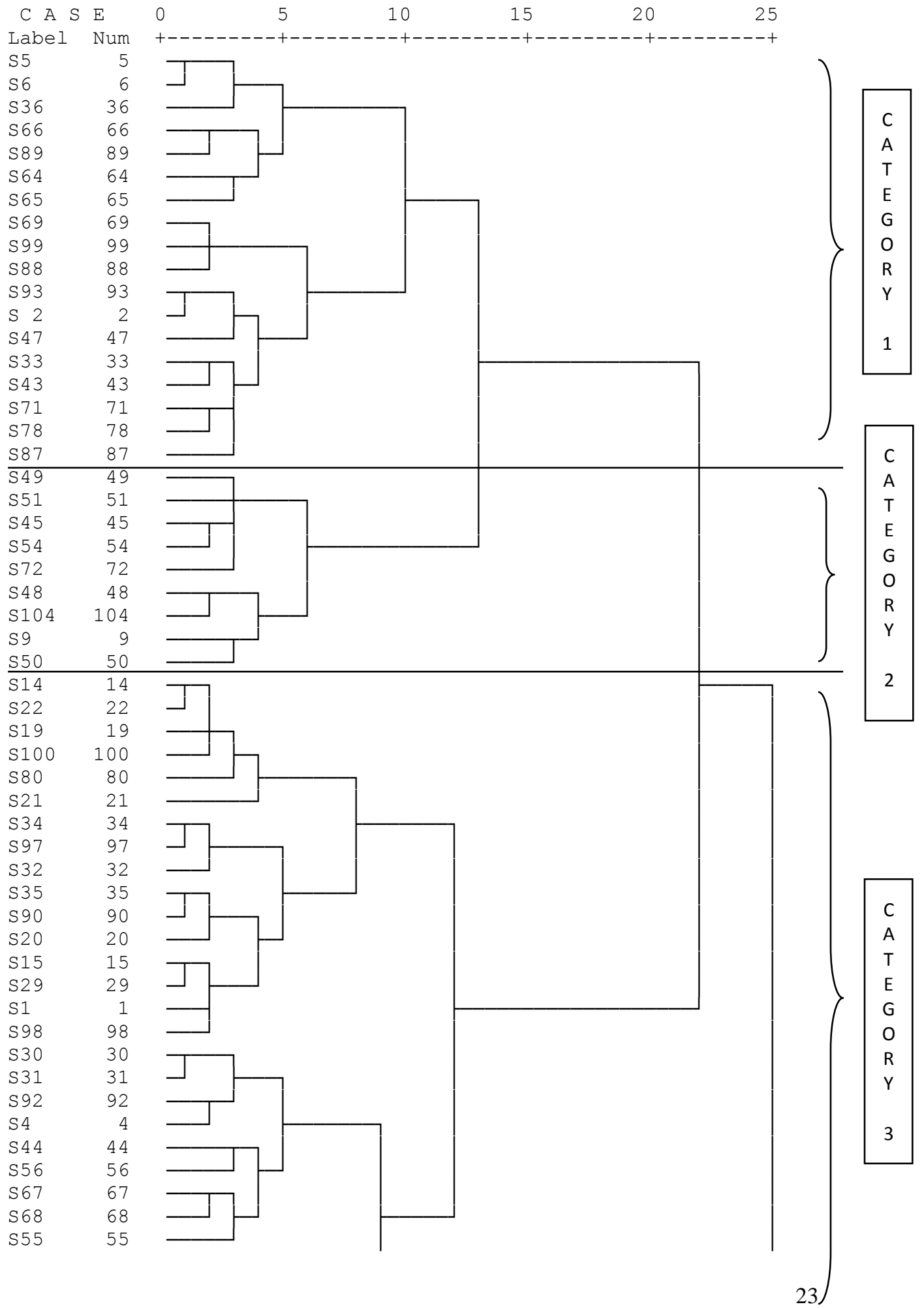


Muhammad Nor A. N., Abdullah S. A.: Developing urban green space classification system using multi-criteria: The case of Kuala Lumpur City, Malaysia

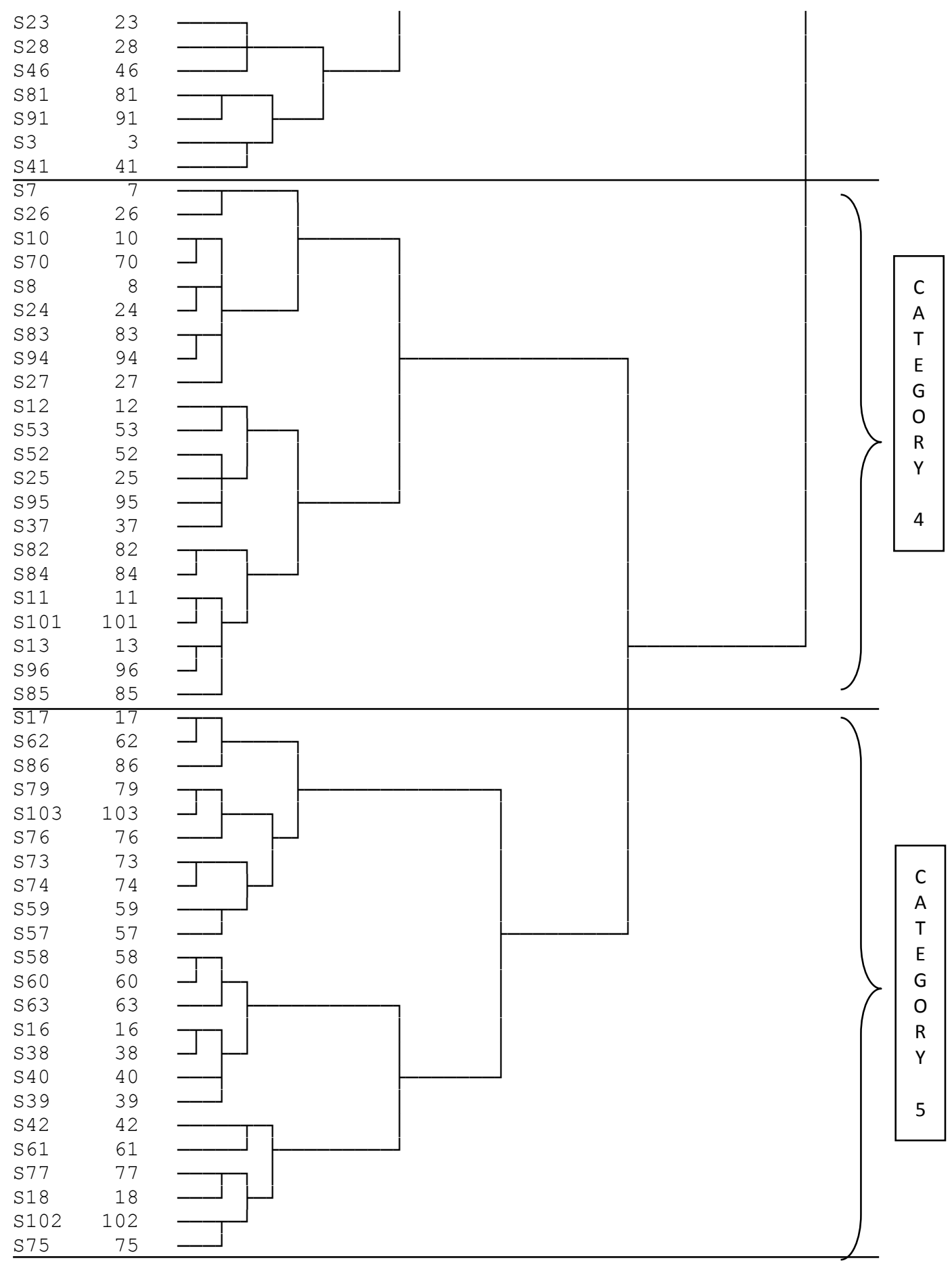




\section{Proportion of each category of urban green space}

The proportion of each category of urban green space in the city and in each strategic zone was calculated using the Eqs. 1 and 2, respectively:

$\%$ of urban green space $i=\frac{\text { Area of urban green space } i}{\text { Total area of urban green space }} \times 100 \%$

$\%$ of urban green space $i$ in zone $j: \underline{\text { Area of green space } i \text { in zone } j} \times 100 \%$

Total area of green space in zone $j$

where, $i$ is category of urban green space and $j$ is strategic zone in the study area.

\section{Landscape pattern analysis of each category of urban green space}

Landscape pattern analysis was conducted to interpret the useful of the systematic classification for urban green spaces planning and management. In this analysis landscape pattern analysis was conducted for the whole city and each strategic zone. Three landscape metrics were chosen and they were the number of patches (NP), patch density (PD) and mean patch area (Area_MN). All landscape metrics were calculated using FRAGSTAT 3.3 (McGarigal et al., 2002).

\section{RESULTS}

\section{Cluster analysis}

Five categories of urban green space were identified through cluster analysis. They are i) conservation green space, ii) greenway, iii) community green space, iv) residential green space and v) amenity green space. The definition and description of each category of urban green space is given in Table 4. 
Muhammad Nor A. N., Abdullah S. A.: Developing urban green space classification system using multi-criteria: The case of Kuala Lumpur City, Malaysia

Table 4: Definition and description of each category of urban green space

\begin{tabular}{|c|c|c|c|}
\hline Category & Abbreviation & Definition & Description \\
\hline $\begin{array}{l}\text { Conservation green } \\
\text { space (example: } \\
\text { urban forest reserve) }\end{array}$ & $\mathrm{CV}$ & $\begin{array}{l}\text { This green space is } \\
\text { significant for natural } \\
\text { resource conservation; } \\
\text { protection of flora and } \\
\text { fauna, education and } \\
\text { aesthetic value. }\end{array}$ & $\begin{array}{l}\text { The size is huge and free from } \\
\text { development. Open to public } \\
\text { and not bordering residential } \\
\text { areas. Ecological value is high } \\
\text { and consists of natural and } \\
\text { planted vegetation and has } \\
\text { recreational facility. }\end{array}$ \\
\hline $\begin{array}{l}\text { Greenway (example: } \\
\text { strips of land, road } \\
\text { and highway, } \\
\text { stream, parcel of } \\
\text { land) }\end{array}$ & GW & $\begin{array}{l}\text { Greenway is green } \\
\text { vegetation area along } \\
\text { main road, railroad, river, } \\
\text { cemetery and } \\
\text { undeveloped area. To } \\
\text { protect from built up area } \\
\text { expansion and help in } \\
\text { urban regeneration. }\end{array}$ & $\begin{array}{l}\text { Designed landscape with buffer } \\
\text { tree, avenue tree, ornamental } \\
\text { tree and shrub. Medium } \\
\text { ecological value and give } \\
\text { aesthetic value. }\end{array}$ \\
\hline $\begin{array}{l}\text { Community green } \\
\text { space (example: } \\
\text { public park such as } \\
\text { regional park, } \\
\text { district park, local } \\
\text { park, neighborhood } \\
\text { garden) }\end{array}$ & $\mathrm{COM}$ & $\begin{array}{l}\text { Community green space is } \\
\text { a unique park with beauty } \\
\text { landscape located near } \\
\text { residential areas and } \\
\text { offices. Equipped with } \\
\text { playground for local } \\
\text { recreational facility and } \\
\text { provide aesthetic value. }\end{array}$ & $\begin{array}{l}\text { Various in size and closed to } \\
\text { housing estates and offices. } \\
\text { This area is planted with shade } \\
\text { trees, shrub and grassland. } \\
\text { Medium ecological value. }\end{array}$ \\
\hline $\begin{array}{l}\text { Residential green } \\
\text { space (example: } \\
\text { house yard, } \\
\text { playground, public } \\
\text { seating area, } \\
\text { residential garden) }\end{array}$ & RES & $\begin{array}{l}\text { Residential green space is } \\
\text { miniature park planted } \\
\text { with trees and equipped } \\
\text { with playground. Located } \\
\text { at residential areas and } \\
\text { can be used by both } \\
\text { children and adults. }\end{array}$ & $\begin{array}{l}\text { The size is usually less than } 2 \\
\text { ha and bordering residential } \\
\text { area. The required facility is } \\
\text { minimal which includes bench } \\
\text { and pavement with short and } \\
\text { shading trees. Medium } \\
\text { ecological value. }\end{array}$ \\
\hline $\begin{array}{l}\text { Amenity green space } \\
\text { (example: football } \\
\text { field, stadium, golf } \\
\text { course) }\end{array}$ & $\mathrm{AM}$ & $\begin{array}{l}\text { Amenity green space is a } \\
\text { multi-purpose green space } \\
\text { which provides facilities } \\
\text { such as football field, golf } \\
\text { course and stadium for } \\
\text { sports and games. }\end{array}$ & $\begin{array}{l}\text { Ecological value is low and } \\
\text { consist grassland/meadow. The } \\
\text { size is varied. It is for formal } \\
\text { and informal recreational } \\
\text { activity. }\end{array}$ \\
\hline
\end{tabular}




\section{Distribution of each category of urban green space}

Fig. 3 shows the distribution of each category of urban green space in Kuala Lumpur City. The total area covered by urban green spaces is 1,288.4 ha or $5.4 \%$ of the total land area of the city. The proportion of amenity green space is the highest $(34.5 \%)$, followed by community green space (31.2\%) and conservation green space (30.9\%) (Fig. 4).

Fig. 3: Distribution of each category of urban green spaces in Kuala Lumpur City.

S-M: Sentul-Manjalara, BTR-SB: Bandar Tun Razak-Sungai Besi, WM-M: Wangsa Maju-Maluri, BJ-S: Bukit Jalil-Seputeh, D-P: Damansara-Penchala, PB - Pusat Bandar

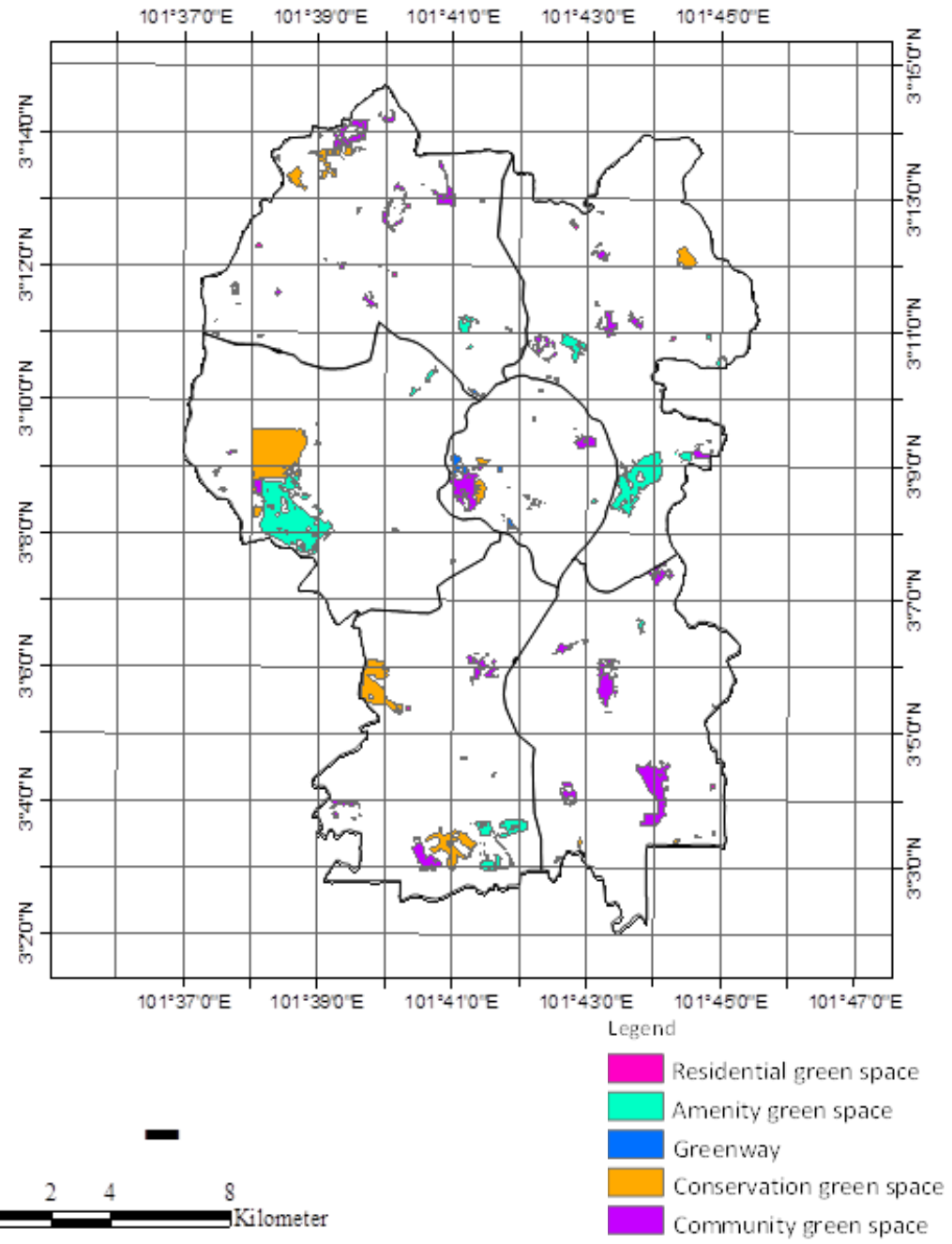

The proportion of residential green space and greenway however is only one percent (Fig. 4). The distribution and composition of urban green space is varied between the six strategic zones. Generally, the highest proportion of urban green space is in Damansara-Penchala whereas the lowest is in Bandar Tun Razak-Sungai Besi (Fig. 5). 
Fig. 4: Proportion of each category of urban green space in Kuala Lumpur City.

CV - Conservation green space, GW - Greenway, COM - Community green space,

RES - Residential green space, AM - Amenity green space

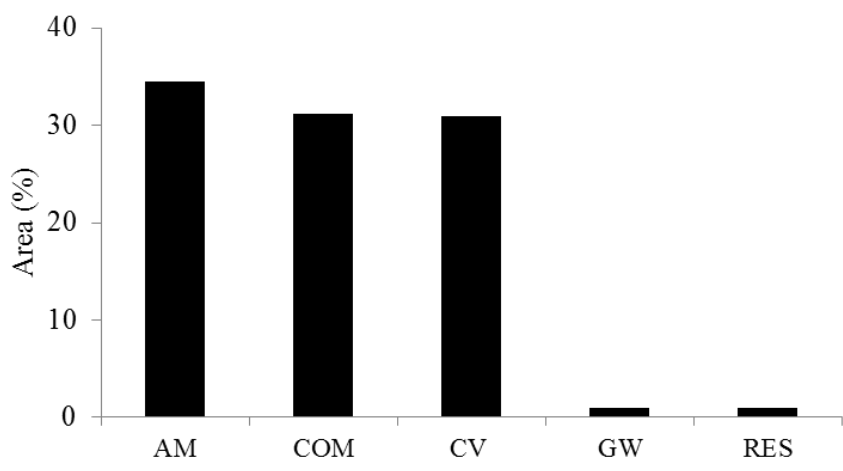

Type of green space

Fig. 5: Proportion of urban green spaces in each strategic zone of Kuala Lumpur City. S-M: Sentul-Manjalara, BTR-SB: Bandar Tun Razak-Sungai Besi, WM-M: Wangsa Maju-Maluri, BJ-S: Bukit Jalil-Seputeh, D-P: Damansara-Penchala, PB - Pusat Bandar

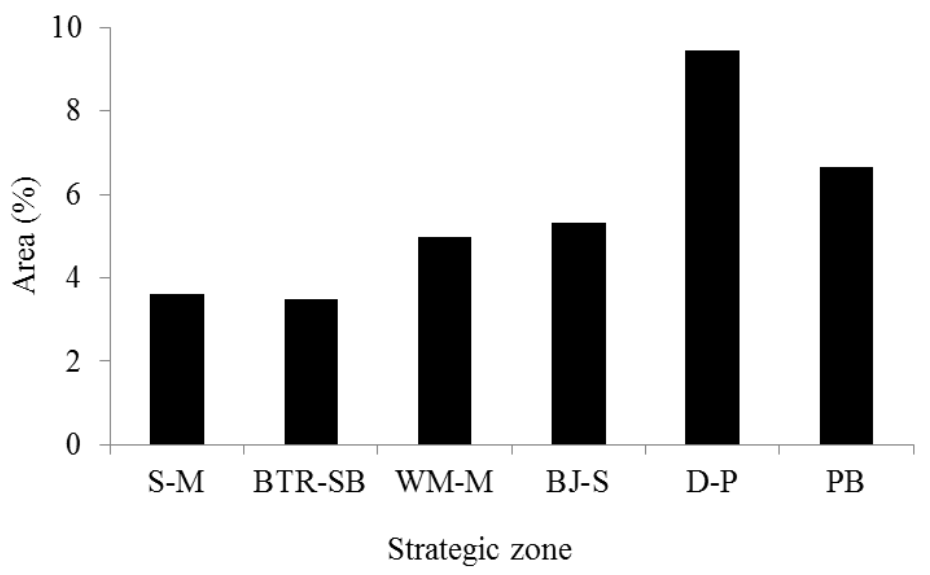

The distribution and composition of each category of urban green space also varied between the six strategic zones. The highest proportion of community green space is in Bandar Tun Razak-Sungai Besi, followed by Pusat Bandar and Damansara-Penchala (Fig. 6). Amenity green space has the highest proportion in Wangsa Maju-Maluri followed by in Sentul-Manjalara and Bukit Jalil-Seputeh. Wangsa Maju-Maluri however has no greenway and the proportion of greenway is very low (0.01-2\%) in Damansara-Penchala, Bandar Tun Razak-Sungai Besi and Sentul-Manjalara. The highest proportion of greenway is in Bukit Jalil-Seputeh followed by in Pusat Bandar. All zones have a low proportion of residential green space, that is, between $0.2 \%$ and $4 \%$. The proportion of conservation green space is low in Wangsa Maju-Maluri, Bandar Tun Razak-Sungai Besi and Bukit Jalil-Seputeh compared with Sentul-Manjalara and Damansara-Penchala which has more than $20 \%$ of the total land area (Fig. 6). 
Fig. 6: Proportion of each category urban green space in each strategic zone.

S-M: Sentul-Manjalara, BTR-SB: Bandar Tun Razak-Sungai Besi, WM-M: Wangsa Maju-Maluri, BJ-S: Bukit Jalil-Seputeh, D-P: Damansara-Penchala, PB - Pusat Bandar

$\mathrm{CV}$ - Conservation green space, GW - Greenway, COM - Community green space,

RES - Residential green space, AM - Amenity green space

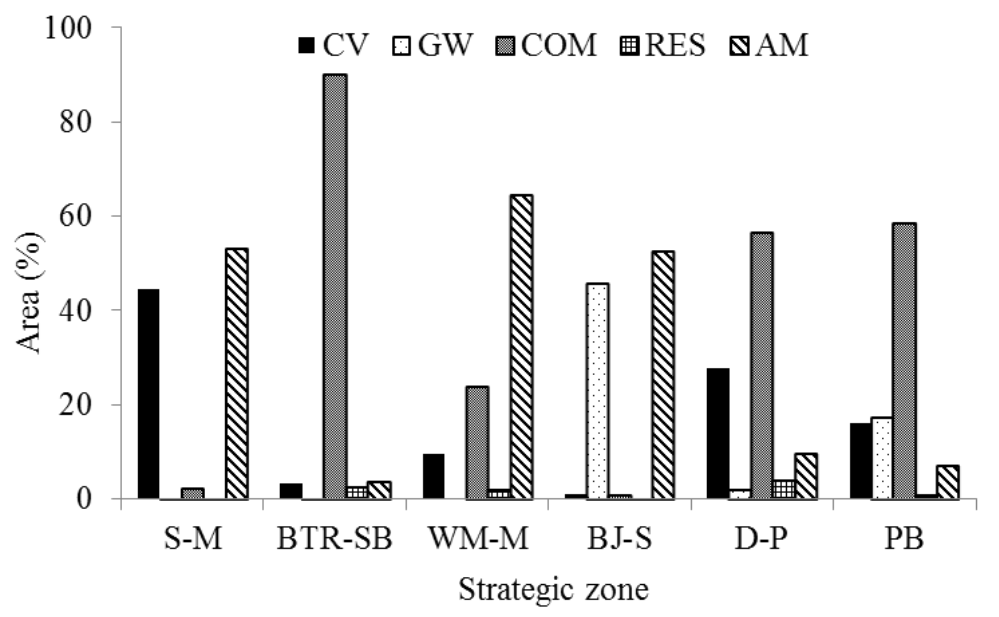

\section{Landscape pattern of each category of urban green space}

Landscape pattern analysis revealed that community green space has the highest number of patches and patch density followed by amenity green space, conservation green space and residential green space while greenway is the lowest (Figs. 7a,b). Conservation green space has the largest mean patch area, followed by amenity green space, community green space and greenway while the lowest is residential green space (Fig. 7c).

Fig. 7: Landscape pattern of each category of urban green space in Kuala Lumpur City.

a)

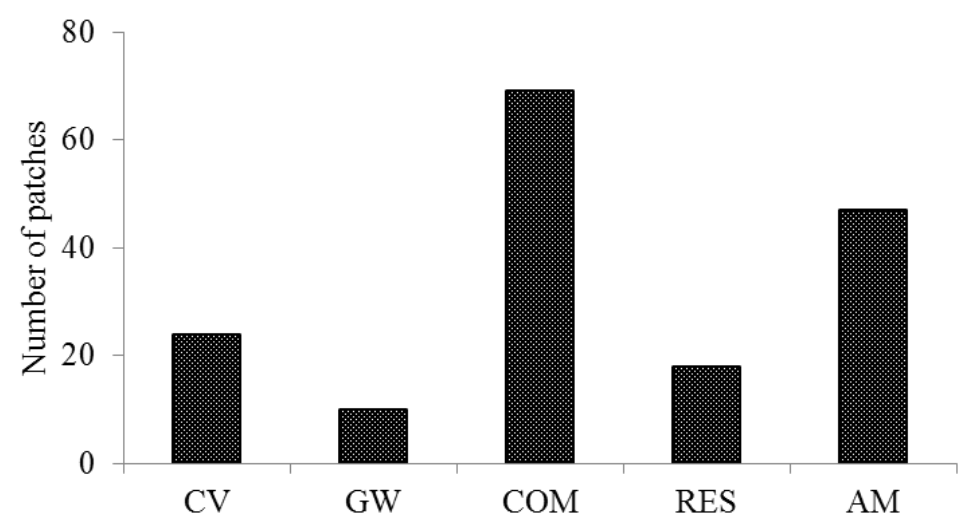

Type of green space 
b)

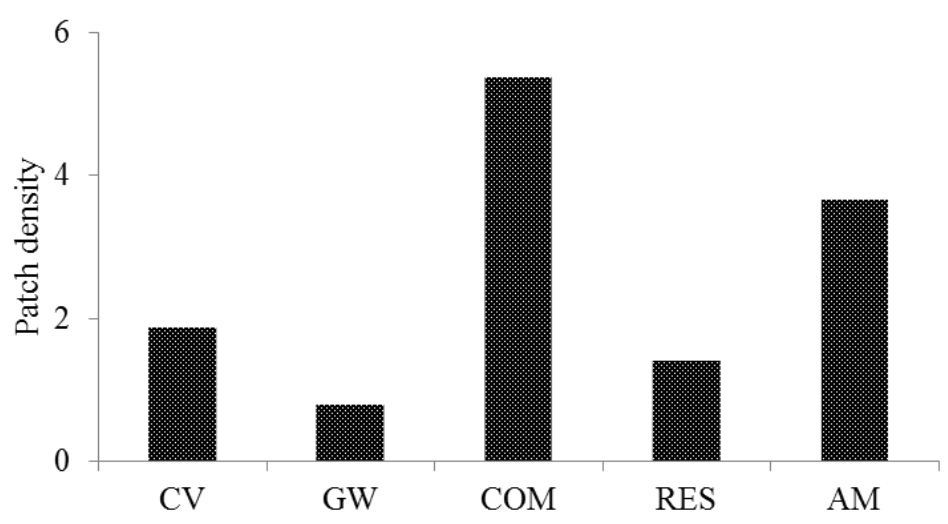

Type of green space

c)

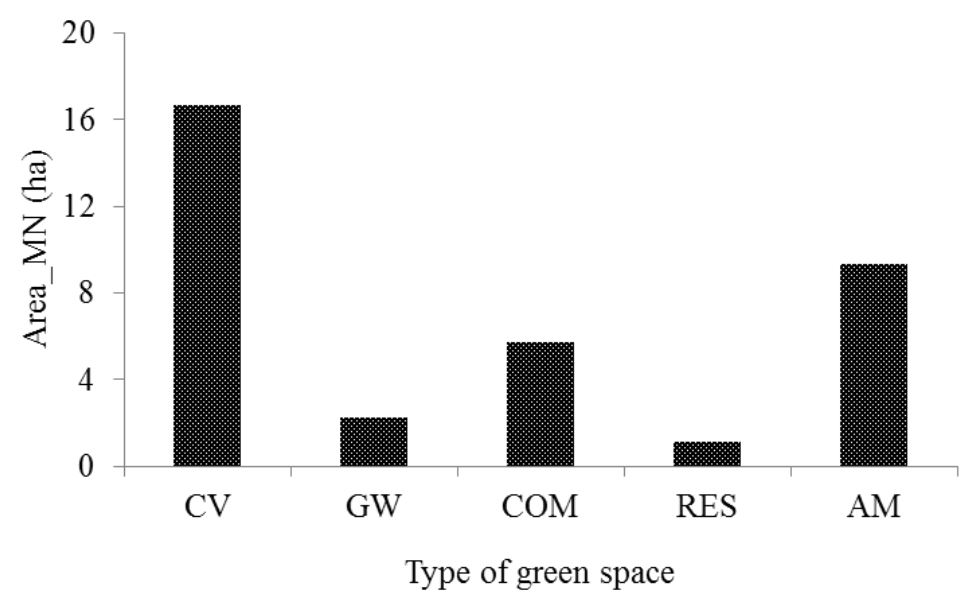

The highest number of patches and patch density of community green space is in Wangsa Maju-Maluri (Table 5). Damansara-Penchala and Bandar Tun Razak-Sungai Besi also has a considerable number of patches and patch desnity of community green space. The number of patches of amenity green space in Sentul-Manjalara, Wangsa Maju-Maluri and Pusat Bandar is similar. However, patch density is obviously higher in Pusat Bandar than that of Sentul-Manjalara and Wangsa Maju-Maluri. Damansara-Penchala has the highest number of patches and patch density of conservation green space. This followed by Sentul-Manjalara and Bandar Tun Razak-Sungat Besi but patch density in the latter is higher than in the former. Bukit Jalil-Seputeh, Damansara-Penchala and Pusat Bandar has a similar number of patches of greenway but patch density at Pusat Bandar is obviously higher than the two strategic zones (Table 5). Among the larger mean patch area is conservation green spaces in Sentul Manjalara and Wangsa Maju-Maluri whereas the fairly larger mean patch area is conservation green space in Bukit Jalil-Seputeh, amenity green space in Sentul-Manjalara and Wangsa Maju-Maluri, and community green space in Pusat Bandar. 
Table 5: Landscape pattern of each category of urban green space in each strategic zone

\begin{tabular}{|c|c|c|c|c|c|c|c|}
\hline \multirow{2}{*}{$\begin{array}{l}\text { Landscape } \\
\text { metrics }\end{array}$} & \multirow{2}{*}{$\begin{array}{l}\text { Urban green space } \\
\text { category }\end{array}$} & \multicolumn{6}{|c|}{ Strategic zones in Kuala Lumpur City } \\
\hline & & S-M & BTR-SB & WM-M & BJ-S & D-P & PB \\
\hline \multirow{5}{*}{$\begin{array}{l}\text { Number } \\
\text { of patches }\end{array}$} & $\mathrm{CV}$ & 6 & 5 & 1 & 1 & 10 & 2 \\
\hline & GW & 1 & 1 & 0 & 4 & 5 & 6 \\
\hline & $\mathrm{COM}$ & 5 & 20 & 34 & 12 & 29 & 5 \\
\hline & RES & 1 & 3 & 4 & 1 & 6 & 2 \\
\hline & $\mathrm{AM}$ & 13 & 6 & 13 & 3 & 4 & 12 \\
\hline \multirow{5}{*}{$\begin{array}{l}\text { Patch } \\
\text { density }\end{array}$} & $\mathrm{CV}$ & 1.41 & 3.26 & 0.47 & 0.37 & 6.56 & 1.95 \\
\hline & GW & 0.24 & 0.65 & 0.00 & 3.10 & 3.28 & 5.86 \\
\hline & $\mathrm{COM}$ & 1.18 & 13.05 & 19.03 & 7.08 & 15.90 & 4.89 \\
\hline & RES & 0.24 & 1.96 & 1.87 & 0.31 & 3.94 & 1.95 \\
\hline & $\mathrm{AM}$ & 3.06 & 3.92 & 6.08 & 0.98 & 2.63 & 11.73 \\
\hline \multirow{5}{*}{ Mean patch area } & $\mathrm{CV}$ & 31.49 & 1.04 & 20.52 & 18.43 & 4.22 & 8.22 \\
\hline & GW & 0.05 & 0.71 & 0.00 & 0.92 & 0.70 & 2.95 \\
\hline & $\mathrm{COM}$ & 1.95 & 6.90 & 1.49 & 0.35 & 2.96 & 11.98 \\
\hline & RES & 0.99 & 1.28 & 1.18 & 1.07 & 1.02 & 0.48 \\
\hline & $\mathrm{AM}$ & 17.35 & 0.91 & 10.60 & 9.65 & 3.66 & 0.61 \\
\hline
\end{tabular}

CV - Conservation green space, GW - Greenway, COM - Community green space,

RES - Residential green space, AM - Amenity green space

S-M: Sentul-Manjalara, BTR-SB: Bandar Tun Razak-Sungai Besi, WM-M: Wangsa Maju-Maluri,

BJ-S: Bukit Jalil-Seputeh, D-P: Damansara-Penchala, PB - Pusat Bandar 
Muhammad Nor A. N., Abdullah S. A.: Developing urban green space classification system using multi-criteria: The case of Kuala Lumpur City, Malaysia

\section{DISCUSSION AND CONCLUSIONS}

In this study, the classification system of urban green space for Kuala Lumpur City was developed. Generally, the multi-criteria approach applied in this study can be considered as a first step in introducing a more systematic way to classify or categorize urban green spaces rather than just manually that usually been used in several research related to urban green spaces. It is also to address the issue of inconsistency in definition and characteristics of urban green spaces between city, municipal, state and even the management zone level. It can be suggested that this approach may not be applied only in Kuala Lumpur City but also to the other cities in Malaysia and other countries with some improvement and adjustment in the criteria selection that suit to their socio-economic and environment.

The criteria/sub-criteria that represents the structure and function of urban green spaces has defined and characterized each category in the classification system. Thus, understanding the definition and characteristics of each category is important for urban planners to improve effectiveness in urban green space planning and management. This is because it may help urban planners to identify what category of urban green space need to be developed to suit the present socio-economic and environment of a particular city. It is also useful to prioritize which category of urban green space that needs attention to improve their quality and quantity as well as to protect them from any land use development. In fact, studies by Kimpton (2017) in a capital city of Australia revealed that employing systematic classification of urban green spaces can improve our understanding of the association between social equity and urban green spaces provision. Thus, this kind of information are crucial in formulating urban development policy which ultimately to achieve sustainable urban development.

This study showed that residential green space category has small and low quality (i.e low ecological value) patches while conservation green space is vice-versa. This means that conservation green space has a great potential for ecological connectivity and urban ecological function compared to residential green space. Therefore, in the context of urban planning and management, conservation green space should be a priority to protect from the expansion of built-up area. Nonetheless, residential green space can not be neglected because it is still significant to residences in their daily life and become one of the important components of their urban green space system (Melasutra, 2003). This revealed that even though they have different quality of structure (i.e size) but in term of function both are important for environmental sustainability and the well-being of urban dwellers point of view. Furthermore, studies by Rudd et al. (2002) at the south Coquitlam and south Port Moody, east of the Vancouver City showed that urban green spaces of residential area (i.e backyard habitat, planted boulervard) is important for biodiversity conservation strategies as it strengthening the habitat network.

The standardization is also useful to make comparison between different strategic zones. For example is the link between the category of urban green spaces and the socio-economic of urban dwellers in a particular strategic zone. In fact, the socio-economic of urban dwellers and development process are among the factors that determine the type, distribution and composition of urban green spaces (Talarchek, 1990). In this context, Pusat Bandar has the lowest residential green space because the zone is designated mainly for commercial, trade and business development (Salleh \& Ishak, 2002). Meanwhile the proportion of conservation green space is low in Bandar Tun Razak-Sungai Besi and Bukit Jalil-Seputeh zones because many housing and amenity development has been designated on these zones. Usually area with high ecological value and diversity such as conservation green space is beneficial to improve the quality of life of urban dwellers (Konijnendijk et al., 2005; Miller, 1997). 
The standardization of urban green spaces category and definition also help to identify how well they are planned and managed which was interpreted through landscape pattern analysis. As in Sentul-Manjalara, the high number of patches and patch density of amenity green space suggests its well provision of recreational activity for people to engage. The relatively high number of patches and patch density of greenway in Pusat Bandar is due to the effective landscape management along the streets. This is related to an effort taken by the authority as part to improve the infrastructure of Pusat Bandar which is the most developed zone in Kuala Lumpur City (Kuala Lumpur City Hall, 2002). Conservation green space is well nurtured in Wangsa Maju-Maluri and Bukit Jalil-Seputeh as shown by low number of patches and patch density but large mean patch area. Greenway in Bandar Tun Razak-Sungai Besi is potential to disappear as shown by the low number of patches, patch density and mean patch area and a similar situation shown by residential green space. Although residential green space has small size their locality is close to residential areas and office buildings which indicate their important provision of recreational activity and healthy environment for people to enjoy (Melasutra, 2004).

Generally, identifying, defining and characterizing different category of urban green spaces systematically and understanding their landscape patterns is necessary to avoid continuous reduction due to highly development in Kuala Lumpur city. The standardization of category and definition of urban green space among different strategic zones allow a quick protocol to identify urban green spaces that critically affected by urban land use development which then can be considered as a priority to prevent further encroachment by development activity. Therefore, the classification system can be used as a guide to coordinate the planning and management of urban green spaces in each strategic zone of Kuala Lumpur City and part of the important components in implementing sustainable development strategies of Kuala Lumpur City.

\section{ACKNOWLEDGEMENTS}

We would like to thank Universiti Kebangsaan Malaysia for providing funding for this project under research grant UKM-OUP-ASPL-6/2007. We also would like to thank to the anonymous reviewer for valuable comments and suggestions. Special thanks are also due to members of Landscape Ecology Group for their support and assistance throughout this project.

\section{REFERENCES}

Akay, A. E., Karas, I. R., \& Gundogan, R. (2007). Classification of tree and shrub species in KSU research and application forest in Kahramanmaras, Turkey. In 10th International Symposium on Physical Measurements and Spectral Signatures in Remote Sensing (pp. 334337). International Archives of The Photogrammetry, Remote Sensing and Spatial Information Sciences.

Apan, A., Raine, S.R., \& Paterson, M.S. (2000). Image analysis techniques for assessing landscape structural change: A case study of the Lockyer Valley catchment, Queensland. In Proceedings of the $10^{\text {th }}$ Australasian Remote Sensing and Photogrammetry Conference ( pp. 438-455), Adelaide, Australia.

Badiru, A.I., Rodríguez, A.C.M., \& de Pires, M.A.F. (2005). The 'Urbanforest' and 'Green space' Classification Model in the Spatial Arrangement of Registro-SP, Brazil. 45th Congress of the European Regional Science Association: "Land Use and Water Management 
Muhammad Nor A. N., Abdullah S. A.: Developing urban green space classification system using multi-criteria: The case of Kuala Lumpur City, Malaysia

in a Sustainable Network Society", Amsterdam, The Netherlands.

Bilgili, B.C., \& Gökyer, E. (2012). Urban Green Space System Planning, Landscape Planning, Dr. Murat Ozyavuz (Ed.), ISBN: 978-953-51-0654-8, InTech, Retrieved September 5, 2012, from from:http://www.intechopen.com/books/landscape-planning/ urban-green-space-system-planning

Bunnel, T., Barter, P.A., \& Morshidi, S. (2002). Kuala Lumpur metropolitan area: A globalizing city-region. Cities, 19, 357-370.

Byrne, J., \& Sipe, N. (2010). Green and open space planning for urban consolidation-A review of the literature and best practice. Urban Research Program, Issues papers 11. Griffith University, Brisbane, Australia.

Dunnett, N., Swanwick, C., \& Woolley, H. (2002). Improving urban parks, play areas and green spaces. Department for Transport, Local Government and the Regions, London.

Department of Statistic Malaysia (2017). Department of Statistic Malaysia, Retrieved September 8, 2017, from http://www.dosm.gov.my

ERDAS. (1999). Field Guide. 5th edition, ERDAS, Inc., Atlanta, Georgia, USA.

Gaffin, S.R., Khanbilvardi, R., \& Rosenzweig, C. (2009). Communication development of a green roof environmental monitoring and meteorological network in New York City. Journal of Forestry Research, 20, 79-82.

Jensen, J.R. (1996). Introductory Digital Image Processing: A Remote Sensing Perspective. Prentice Hall, New Jersey.

Kimpton, A. (2017). A spatial analytic approach for classifying greenspace and comparing greenspace social equity. Applied Geography, 82, 129-142.

Kong, F., \& Nakagoshi, N. (2006). Spatial-temporal gradient analysis of urban green spaces in Jinan, China. Landscape and Urban Planning, 78, 147-164.

Konijnendijk, C.C., Ricard, R.M., Kenney, A., \& Randrup, T.B. (2005). Defining urban forestry. A comparative perspective of North America and Europe. Urban Forestry \& Urban Greening, 4, 93-103.

Kuala Lumpur City Hall (2002). Kuala Lumpur Landscape Master Plan. Kuala Lumpur City Hall, Kuala Lumpur, Malaysia.

Kuala Lumpur City Hall (2004). Kuala Lumpur Structural Plan 2020. Percetakan Nasional Berhad, Kuala Lumpur, Malaysia.

Lee, A.C.K., Jordon, H.C., \& Horsley, J. (2015). Value of urban green spaces in promoting healthy living and wellbeing: prospects for planning. Risk Management and Healthcare Policy, 8, 131-137.

Liu, J. (2000). Smoothing filter-based intensity modulation: A spectral preserve image fusion technique for improving spatial details. International Journal of Remote Sensing, 21,3461-3471.

Malaysia (2001). Rancangan Malaysia Ke-10, 2001-2006. Unit Perancang Ekonomi. Kuala Lumput (in Malay).

McGarigal, K., Cushman, S.A., Neel, M.C., \& Ene, E. (2002). FRAGSTATS: Spatial Pattern Analysis Program for Categorical Maps. University of Massachusetts, Amherst.

Melasutra, M.D. (2003). Residential Local Parks in Kuala Lumpur: Their Particular Functions. International Human Development Programme Yearly Book. Bonn, Germany.

Melasutra, M. D. (2004). Urban Open Spaces Uses as a Function of Lifestyle and Space 
Characteristics: the Malaysian Context. Paper presented at the International Conference on Open Space: People Space, Edinburgh, United Kingdom.

Miller, R.W. (1997). Urban Forestry: Planning and Managing Urban Greenspaces. Prentice Hall, New Jersey, USA.

Owen, S.M., MacKenzie, A.R., Bunce, R.G.H., Stewart, H.E., Donovan, R.G., Stark, G., \& Hewit, C.N. (2006). Urban land use classification and its uncertainties using principle component and cluster analyses: A case study for the UK West Midlands. Landscape and Urban Planning, 78, 311-321.

Panduro, T.E., \& Veie, K.L. (2013). Classification and valuation or urban green spaces - A hedonic price valuation. Landscape and Urban Planning, 120, 119-128.

Pauleit, S., \& Kaliszuk, E. (2005). Green Structure Patterns - Green Structure and Urban Planning. Report of COST Action C11 - Green Structure and Urban Planning, European Commission.

Peña-Salmón, C., Leyva-Camacho, O., Rojas-Caldelas, R., Alonso-Navarrete, A., \& Iñiguez-Ayón, P. (2014). The identification and classification of green areas for urban planning using multispectral images at Baja California, Mexico. WIT Transaction on Ecology and The Environment, 191, 611-621.

Pham, U.D., \& Nakagoshi, N. (2008). Application of land suitability analysis and landscape ecology to urban greenspace planning in Hanoi, Vietnam. Urban Forestry and Urban Greening, 7, 25-40.

Rudd, H., Vala, J., \& Schaefer, V. (2002). Importance of backyard habitat in a comprehensive conservation strategy: A connectivity analysis of urban green spaces. Restoration Ecology, 10, 368-375.

Salleh, M.N., \& Ishak, M.Y. (2002). Greening our cities: Challenges and Opportunities. $18^{\text {th }}$ EAROPH World Planning Congress. Kuala Lumpur.

Senanayake, I.P., Welivitiya, W.D.D.P., \& Nadeeka, P.M. (2013). Urban green spaces analysis for development planning in Colombo, Sri Lanka, utilizing THEOS satellite imagery - A remote sensing and GIS approach. Urban Forestry \& Urban Greening, 12, 307-314.

Sreenivasalu, V., \& Bhaskar, P.U. (2010). Change detection in land use and land cover using remote sensing and GIS techniques. International Journal of Engineering Science and Technology, 2,7758-7762.

Talarchek, G.M. (1990). The urban forest of New Orleans: an exploratory analysis of relationships. Urban Geography, 11, 65-86.

Tratalos, J., Fuller, R.A., Warren, P.H., Davies, R.G., \& Gaston, K.J. (2007). Urban form, biodiversity potential and ecosystem services. Landscape and Urban Planning, 83, 308-317.

Turner, M.G., Gardner, R.H., \& O’Neill, R.V. (2001). Landscape Ecology in Theory and Practice: Pattern and Process. Springer, New York.

Ummeh, S., \& Toshio, K. (2017). Classification of urban parks and their regional characteristics in Dhaka City, Bangladesh. Journal of Environmental Science and Engineering B, 6, 41-54.

Vatseva, R., Kopecká, M., Otahel, J., Rosina, K., Kitev, A., \& Genchev, S. (2016). Mapping urban green spaces based on remote sensing data: case studies in Bulgaria and Slovakia. In Proceedings of 6th International Conference on Cartography and GIS (pp. 569-578), Albena, Bulgaria. 
Wang, J. (2009). Prospects for urban forests in enhancing carbon sequestration and integrated assessment issues of urban forests values. Technical pages for the Joint Urban Remote Sensing Event.

Xie, Y., Fang, C., Lin, G., Gong, H., \& Qiao, B. (2007). Tempo-spatial patterns of land use changes and urban development in globalizing China: A study of Beijing. Sensors, 7, 2881-2907.

Yüksel, A., Akay, A.E. \& Gundogan, R. (2008). Using ASTER imagery in land use/cover classification of eastern mediterranean landscapes according to CORINE land cover project. Sensors, 8,1237-1251.

Zhang, L., Liu, Q., Hall, N.W., \& Fu, Z. (2007). An environmental accounting framework applied to green space ecosystem planning for small towns in China as a case study. Ecological Economics, 60, 533-542.

Zhang, W., Zhang, X., Li, L., \& Zhang, Z. (2007a). Urban forest in Jinan City: Distribution, classification and ecological significance. CATENA, 69, 44-50. 